\title{
ESTUDO DO NÚMERO DE ALUNOS COM TRANSTORNOS DO ESPECTRO AUTISTA DO ENSINO FUNDAMENTAL NO NÚCLEO REGIONAL DE UMUARAMA - PR
}

\author{
Jordhan Emmanuel Marciano da Silva ${ }^{1}$ \\ Renato Felipi Ferreira Benatti ${ }^{2}$ \\ Leonardo Morini ${ }^{3}$ \\ Isabella Piologo Van $\mathrm{Dal}^{4}$ \\ Leticia Meireles de Souza ${ }^{5}$ \\ Gleicieli Karine dos Reis Dias ${ }^{6}$ \\ Rosangela Bressan Buosi ${ }^{7}$ \\ Arnaldo Gomes do Amaral ${ }^{8}$
}

SILVA, J. E. M. da; BENATTI, R. F. F.; VAN DAL, I. P.; SOUZA, L. M. de; DIAS, G. K. dos R.; BUOSI, R. B.; AMARAL, A. G. do. Estudo do número de alunos com transtornos do espectro autista do Ensino Fundamental no núcleo regional de Umuarama - Pr. EDUCERE - Revista da Educação, Umuarama, v. 19, n. 2, p. 313-322, jul./dez. 2019.

RESUMO: O projeto visou o mapeamento de informações sobre a quantidade de alunos com avaliação de Transtornos do Espectro Autista nas escolas pertencentes ao Núcleo Regional de Educação de Umuarama $\mathrm{PR}$, bem como a quantidade de professores que possuem formação específica para o trabalho com esses alunos. $\mathrm{O}$ trabalho foi realizado mediante pesquisa documental, junto ao NRE de Umuarama, em que conta com 06 (seis) alunos diagnosticados com autismo e 06 (seis) professores PAEE (Professor de Apoio Educacional Especializado) que fazem o atendimento especializado auxiliando esses alunos. No total estão disponibilizadas 82 salas de Recursos Multifuncionais Tipo I.

\footnotetext{
DOI: 10.25110/educere.v19i2.2019.6825

${ }^{1}$ Acadêmico do Curso de Sistemas de Informação da UNIPAR - PIC, jordhanemmanuel@gmail.com ${ }^{2}$ Acadêmico do Curso de Sistemas de Informação da UNIPAR - PIC, renato.benatti@edu.unipar.br ${ }^{3}$ Acadêmico do Curso de Sistemas de Informação da UNIPAR - PIC, leo.morini.nn@gmail.com ${ }^{4}$ Acadêmica do Curso de Psicologia da UNIPAR - PIC, isabella.v@edu.unipar.br ${ }^{5}$ Acadêmica do Curso de Pedagogia da UNIPAR - PIC, leticialms09@gmail.com ${ }^{6}$ Acadêmica do Curso de Pedagogia da UNIPAR - PIC, gleicikarine.16@gmail.com ${ }^{7}$ Docente da UNIPAR, robressan@prof.unipar.br

${ }^{8}$ Docente da UNIPAR, arnaldo@prof.unipar.br
} 
PALAVRAS-CHAVE: Inclusão; Autismo; Sala de Recurso Multifuncional - Tipo I.

\title{
THE NUMBER OF STUDENTS IN THE AUTISTIC SPECTRUM WITHIN THE ELEMENTARY EDUCATION IN THE REGIONAL DEPARTMENT OF UMUARAMA - PR
}

\begin{abstract}
The project aimed at obtaining information on the number of students suffering from Autism Spectrum Disorder in the schools belonging to the Umuarama Regional Education Department - PR (NRE), as well as the number of teachers who have specific training to work with this students. The work was developed through documentary research, together with the Umuarama NRE, where it is stated that there are 6 (six) students diagnosed with autism and 6 (six) PAEE teachers (Specialized Educational Support Teacher) who provide specialized assistance to these students. A total of 82 Multifunctional Type I facilities are available.

KEYWORDS: Inclusion; Autism; Multifunctional Resource Room Type I.

\section{ESTUDIO DEL NÚMERO DE ESTUDIANTES CON TRASTORNOS DEL ESPECTRO AUTISTA EN LA ENSEÑANZA PRIMARIA EN EL NÚCLEO REGIONAL DE EDUCACIÓN DE UMUARAMA - PR}

RESUMEN: El proyecto ha buscado el mapeo de informaciones sobre la cantidad de estudiantes con evaluación de Trastorno del Espectro Autista en las escuelas que pertenecen al Núcleo Regional de Educación de Umuarama - PR, así como la cantidad de profesores que tienen capacitación específica para trabajar con esos estudiantes. El estudio se realizó a través de investigación documental, junto al NRE de Umuarama, en el cual hay 06 (seis) estudiantes diagnosticados con autismo y 06 (seis) profesores PAEE (Profesor de Apoyo Educativo Especializado) que hacen asistencia especializada a esos estudiantes. Están disponibles 82 salas de Recursos Multifuncionales Tipo I.

PALABRAS CLAVE: Inclusión; Autismo; Sala de Recurso Multifuncional - Tipo I. 


\section{INTRODUÇÃO}

Este trabalho teve como objetivo fazer um levantamento entre as escolas estaduais de ensino fundamental do Núcleo Regional de Educação de Umuarama, sobre a quantidade de alunos com diagnóstico de Transtornos do Espectro Autista que estão matriculados no Ensino Regular e recebem auxílio do Professor de Apoio Educacional Especializado e qual a especialização desse professor. A intenção da pesquisa foi verificar diante da fala de muitos professores da rede pública estadual, que os casos de autismo vêm aumentando consideravelmente. Relatam ainda que diante da falta de informações sobre o processo educacional, pais e comunidade têm-se mobilizado para buscar profissionais que possam trabalhar com os educadores, fornecendo-lhes informações sobre a prática pedagógica em sala de aula, bem como informações sobre os procedimentos, cuidados e educação que a família deve dispensar com seus filhos diagnosticados com Transtornos do Espectro Autista.

Diante do exposto, viu se a necessidade de um levantamento de quantos casos existem de alunos com Transtornos do Espectro Autista no Núcleo Regional de Umuarama, quantos são atendidos nas Salas de Recursos Multifuncionais Tipo I, quantos estão matriculados no Ensino Fundamental, realizar uma classificação do número total de alunos por escola que tem diagnóstico de Transtornos do Espectro Autista e verificar o número de profissionais com cursos de especialização específica para área do autismo.

\section{FUNDAMENTAÇÃO TEÓRICA}

Em 1943, um psiquiatra infantil, Leo Kanner, da John Hopkins University (E.U.A.), descreveu um grupo de crianças gravemente lesadas que tinham certas características comuns. A mais notada era a incapacidade de se relacionar com pessoas. Ele utilizou o adjetivo empregado por Plouller e intitulou o seu trabalho de "Autistic Disturbance of Affective Contact" (Distúrbio Autístico do Contato Afetivo). Usou, pois, esta palavra para descrever a qualidade de relacionamento daquelas crianças (nota: autismo para descrever autossuficiente) (SILVA, 2016).

Desde então, o autismo passou e passa por um constante proces- 
so de investigação no que diz respeito à sua definição. De acordo com Teixeira (2006), o autismo é um Transtorno Invasivo do desenvolvimento caracterizado por prejuízos na interação social, atraso na aquisição de linguagem e passível de comportamentos estereotipados e repetitivos. Descrito pelo médico e professor da Johns Hopkins University, o austríaco Leo Kanner, em 1943. O autor aponta ainda, que a incidência é de dois a cinco casos para cada dez mil crianças e ocorre, em torno de quatro vezes mais em meninos do que em meninas. Não se conseguiu até agora provar qualquer causa psicológica no meio ambiente dessas crianças, que possa causar a doença.

Segundo definição da "The National Society for Autistic Children"- USA- 1978 -“Autismo é uma inadequacidade no desenvolvimento que se manifesta de maneira grave, durante toda vida. É incapacitante e aparece, tipicamente, nos três primeiros anos de vida. Acontece em cerca de 05 entre 10.000 (dez mil) nascidos e é quatro vezes mais comum entre meninos do que em meninas. É encontrada em todo mundo e em famílias de toda configuração racial, étnica e social. Não se conseguiu provar nenhuma causa psicológica no meio ambiente dessas crianças que possa causar o autismo". Apesar de estar fazendo uso desta definição, faz-se indispensável registrar que houve mudanças de prevalência. (SANTOS, 2008)

Para Mello (2007) Autismo é um distúrbio do desenvolvimento que se caracteriza por alterações presentes desde idade muito precoce, tipicamente antes dos três anos de idade, com impacto múltiplo e variável em áreas nobres do desenvolvimento humano como as áreas de comunicação, interação social, aprendizado e capacidade de adaptação.

Segundo Teixeira (2006), a síndrome de Asperger, um espectro autista, foi descrita pela primeira vez em 1944 pelo médico austríaco Hans Asperger. Ele relatou crianças com déficit na socialização, interesses circunscritos, déficit na linguagem e na comunicação. A síndrome de Asperger também é classificada como um Transtorno Invasivo do Desenvolvimento, um tipo de autismo, no entanto diferentemente do autismo infantil, a criança ou adolescente com esta síndrome pode apresentar desenvolvimento cognitivo e intelectual normal e não apresentar atraso na aquisição da fala. Quando adultos, podem viver de forma comum, como qualquer outra pessoa que não possui a síndrome. 
Hoje, atribui-se tanto a Kanner como a Asperger a identificação do autismo, sendo que por vezes encontramos os estudos de um e de outro associados a distúrbios ligeiramente diferentes. Bem como, o conceito de "autismo infantil" se estendeu a uma patologia mais ampla do que aquela que foi descrita por Leo Kanner e por Asperger. Podemos encontrar estados ou formas autistas denominados hoje como Transtorno do Espectro Autista que podem estar associados a outras patologias, tais como a epilepsia, paralisias cerebrais e síndromes genéticas, dentre outras. Isto torna o diagnóstico difícil e é muito frequente o autismo passar despercebido e ser confundido com outros quadros patológicos. Ainda não se tem instrumental diagnóstico específico para este fim, Mello (2007), relata que o "diagnóstico de autismo é feito basicamente através da avaliação do quadro clínico. Não existem testes laboratoriais específicos para a detecção do autismo. Por isso, diz-se que o autismo não apresenta um marcador biológico". Com isso, pais e professores ficam na dependência da experiência de profissionais especializados para sua identificação. Na maioria dos casos, eles são percebidos na escola, ainda na Educação Infantil, pelas professoras que, no convívio cotidiano e grupal, podem observar a impossibilidade destas crianças de se relacionar, seja com outras crianças, seja com as próprias professoras.

Algumas características comuns em crianças com Transtorno do Espectro Autista, no entanto podem não aparecer em todos os casos: Distúrbios no ritmo, de habilidades físicas, sociais e linguísticas. Tem dificuldade em estabelecer contato com os olhos. Age como se não tomasse conhecimento do que acontece a sua volta. Não se comunica com as outras pessoas. Não explora o ambiente e as novidades e costuma restringir-se e fixar-se em poucas coisas; Reações anormais às sensações. As funções ou áreas mais afetadas são: visão, audição, tato, dor, equilíbrio, olfato, gustação e maneira de manter o corpo. Parece surdo apesar de não ser. Apresenta maneirismo, gestos repetitivos e imotivados como balançar as mãos ou balançar-se; Fala e linguagem ausentes ou atrasadas. Certas áreas específicas do pensar, presentes ou não. Ritmo imaturo da fala. Pode começar a desenvolver a fala e de repente parar. Pouca compreensão de ideias; uso de palavras sem associação com o significado. Ecolalia, repetição de sílabas ou palavras sucessivamente; Relacionamento anormal com os objetivos, eventos e pessoas. Respostas não apropriadas à adultos 
e crianças. Objetos e brinquedos não usados de maneira devida.

As características mais comuns e importantes da síndrome de Asperger que hoje é denominada como um Transtorno do Espectro Autista, podem ser divididas em várias categorias amplas: as dificuldades sociais, os interesses específicos e intensos, e peculiaridades na fala e na linguagem. A principal característica é a dificuldade com o convívio social. Os portadores de Asperger não têm a capacidade de captar informação sobre os estados emocionais de outras pessoas pela expressão facial, linguagem corporal, humor e ironia, o que é às vezes chamado de "cegueira emocional".

Algumas características dos indivíduos com Asperger: podem demonstrar aptidão avançadas demais para sua idade em relação à fala, leitura, matemática, noções de espaço ou música, às vezes no nível de "superdotados", mas estes talentos são contrabalançados por retardamentos consideráveis no desenvolvimento de outras funções cognitivas; Interesses específicos ou preocupações com um tema em detrimento de outras atividades. Às vezes se destaca em uma área de interesse: geografia, matemática, ciências, etc. Como por exemplo, podem se destacar no conhecimento sobre astros, dinossauros, decorar placas de carro ou ainda realizar operações matemáticas complexas; Comportamento robótico e repetitivo; Dificuldade em compreender as mensagens transmitidas por meio da linguagem corporal: Aspergers geralmente não olham nos olhos, e quando olham, não conseguem "ler" os olhos das outras pessoas; Interpretar as palavras sempre em sentido literal: têm dificuldade em identificar o uso de coloquialismos, ironia, gírias, sarcasmo e metáforas;Honestidade e ludibrio: Aspergers são geralmente considerados "honestos demais", "inocentes" ou "sem malícia" e têm dificuldade em enganar ou mentir, mesmo à custa de magoar alguém; Lidar com conflitos: ser incapaz de entender outros pontos de vista pode levar a inflexibilidade e a uma incapacidade de negociar soluções de conflitos; Consciência de magoar os outros: uma falta de empatia em geral leva a comportamentos ofensivos ou insensíveis não-intencionais; Introspecção e autoconsciência: indivíduo com Asperger têm dificuldade de entender seus próprios sentimentos ou o seu impacto nos sentimentos alheios; Vestimenta e higiene pessoal: pessoas com Asperger tendem a ser menos afetadas pela pressão dos semelhantes do que outras. Como resultado, 
geralmente fazem tudo da maneira que acham mais confortável, sem se importar com a opinião alheia. Isto é válido principalmente em relação à forma de se vestir e aos cuidados com a própria aparência; Necessidade crítica: Aspergers sentem-se forçosamente compelidas a corrigir erros, mesmo quando são cometidos por pessoas em posição de autoridade, como um professor ou um chefe. Por isso, podem parecer imprudentemente ofensivos; Exaustão: quando um indivíduo com Asperger começa a entender o processo de abstração, precisa treinar um esforço deliberado e repetitivo para processar informações de outra maneira. Isso muito frequentemente leva a exaustão mental.

\section{MATERIAIS E MÉTODOS}

A pesquisa foi realizada em duas etapas, sendo a primeira etapa uma Pesquisa Documental contando com uma reunião com a Chefia do Núcleo Regional de Educação, - Umuarama, para solicitar a autorização da pesquisa, análise de documentos e assinatura do Termo de Utilização de dados. Na sequência, foi solicitada ao Departamento de Educação Especial, a relação de alunos com diagnósticos de Transtorno do Espectro Autista, onde foi realizado um levantamento do número total de alunos com diagnóstico de Transtorno do Espectro Autista matriculados nas salas de recursos multifuncional - tipo I e quantos são atendidos pelo Professor de Apoio Educacional Especializado - PAEE.

Também foi verificado junto ao NRE o número de professores que possuem cursos específicos para área do autismo. Na segunda etapa foi realizada a Tabulação dos Dados coletados via consulta documental constando o número de alunos com Transtorno do Espectro Autista e o total de professores que possuem cursos específicos para área do autismo.

\section{DESENVOLVIMENTO}

Por meio das visitas realizadas junto ao Departamento de Educação Especial, do Núcleo Regional de Educação de Umuarama e efetuadas análises documentais e dos relatórios de alunos com diagnósticos de Transtorno do Espectro Autista, pôde se constatar que segundo a Secretaria de Educação do Estado do Paraná (SEED) "O Professor de 
Apoio Educacional Especializado (PAEE) atua juntamente com a equipe pedagógica e com o professor de disciplina na definição de estratégias para que o estudante autista tenha acesso ao currículo e adequadas formas de avaliação que permitem a aprendizagem". (PARANÁ, 2016, s/p).

Neste mesmo documento, em entrevista cedida pela professora Mônica Lirani, que trabalha com alunos especiais no Colégio Estadual Professor Elias Abrahão, em Curitiba, diz que "Cabe ao Professor de Apoio fazer os determinados ajustes para que o aluno se enxergue no seu papel como aluno, e o que esse aluno tem para oferecer dentro do seu potencial" (IDEM, 2016, s/p).

A SEED informa que em 2016 houve aproximadamente 500 estudantes com laudo de Transtorno de espectro autista matriculados em salas de aulas comuns.

Segundo o Núcleo Regional de Educação de Umuarama NRE, em todas as cidades pertencentes a sua jurisdição, existem 82 salas de Recursos Multifuncional tipo I para atendimento de alunos com Transtornos Globais de Desenvolvimento, a nomenclatura que era dada antigamente a alunos com Espectro autista. Nestas salas são atendidos alunos com TEA e também alunos com outros tipos de dificuldades em período de contra turno escolar. Foram identificados 06 alunos com laudo de Transtorno do Espectro Autista cursando o Ensino Regular, estes dependem de auxílio especializado. Para o atendimento desses alunos o NRE conta com 06 professores PAEE (Professores de Apoio Educacional Especializado) que realizam o acompanhamento destes alunos dentro das salas do ensino regular. No entanto, estes professores possuem formação especializada em Atendimento Educacional Especializado, a antiga especialização em Educação Especial. Foi informado ainda que nenhum apresenta formação específica para área do Autismo, mas dois estão cursando especialização específica para atendimento a alunos diagnosticados com autismo.

\section{CONSIDERAÇÕES FINAIS}

Conforme afirmação do SEED/PR existem alunos diagnosticados com espectro autista no estado do Paraná sendo atendidos nas escolas de ensino regular. 
No NRE de Umuarama, por meio de seus relatórios constam vários alunos com TEA frequentando o ensino regular, mas que não necessitam de professores PAEE. Estes estudam no ensino regular em um período e em outro recebem atendimento nas Salas de Recursos Multifuncionais Tipo I, somando 82 salas no total. Constatou-se que em todas as escolas pertencentes ao Núcleo Regional de Educação de Umuarama, existem apenas 06 alunos com comprometimento mais avançado que necessitam de professor de Apoio Educacional Especializado em sala de aula. Estes estudam nas salas de ensino regular com apoio do professor especializado e no período contrário de aulas recebe atendimento na Sala de Recurso Multifuncional Tipo I.

Todos os professores possuem especialização para trabalhar com alunos com necessidades especiais, mas nenhum professor tem especialização específica (concluída) para o trabalho com alunos diagnosticados com Transtornos do Espectro Autista matriculados nas Escolas Estaduais de Umuarama e Região. O NRE informou que 02 professores estão cursando especialização específica para Transtornos do Espectro Autista.

Tendo em vista esta pesquisa, o NRE demonstra uma preocupação para o bom atendimento dos alunos autistas, ficando para uma próxima etapa o levantamento de cursos específicos ofertados para formação de profissionais que trabalham com alunos com este tipo de transtorno.

\section{REFERÊNCIAS}

MELlO, A. M. S. R. de. Autismo: guia prático. Disponível em http:// www.autismo.org.br/site/images/Downloads/7guia\%20pratico.pdf. Acesso em: 25 jun. 2016.

\section{PARANÁ. O papel do professor de apoio na Educação Especial.} 14/04/2016. Disponível em: http://www.educacao.pr.gov.br/modules/ noticias/article.php?storyid=6431 Acesso em: 29 nov. 2017.

SANTOS, A. M. T. dos. Autismo: Desafio Na Alfabetização e no Convívio Escolar. Trabalho de Conclusão de Curso apresentado ao CRDA - Centro de Referência em Distúrbios de Aprendizagem, São Paulo, 2008. Disponível em: http://www.crda.com.br/tccdoc/22.pd. Acesso em: 14 jul. 2016. 
SILVA, E. H. C. da. Autismo-BR primeiras descrições. Distúrbios Autísticos do Contato Afetivo. Disponível em: http://www.autismo-br. com.br/home/Inicio.htm. Acesso em: 14 jul. 2016.

TEIXEIRA, G. Transtornos Comportamentais na Infância e Adolescência. São Paulo: Rubio, 2006.

Recebido em: 04/06/18

Aprovado em: 30/05/19 